\title{
A Study on Infectious and Non-Infectious Pulmonary Complications in Autologous Bone Marrow Transplantation
}

\begin{abstract}
Sangram Keshari Mahapatra, Manoranjan Pattnaik, Rabindra Kumar Jena, Jeetendra Kumar Patra*, Bijaya Kumar Meher, Hemanta Kumar Sethy, Thitta Mohanty, Geetanjali Panda, Biswal Pradipta Trilochan, Nrusingha Charan Dash and Paresh Chandra Mahanta
\end{abstract}

Department of Pulmonary Medicine, SCB Medical and Hospital, India

Submission: November 8, 2019; Published: December 02, 2019

*Corresponding author: Jeetendra Kumar Patra, Assistant Professor, Department of Pulmonary Medicine, SCB Medical College and Hospital, Cuttack, Odisha, India, Email: jeetendrakumarpatra@gmail.com

\begin{abstract}
Introduction: Bone Marrow Transplantation is a standard therapy for aplastic anaemia, acute leukaemia's, chronic myelogenous leukaemia, non-Hodgkin's lymphoma and Hodgkin's disease with long-term disease-free survival exceeding 60\% [1]. Encouraging results are also noted in the role of BMT in the management of hemoglobinopathies, immunodeficiency disorders, myelodysplastic syndromes, multiple myeloma and testicular and breast cancers [1]. Pulmonary complications including infectious and non-infectious conditions which occurs in $40 \%-60 \%$ of patients who received BMTs, account for meaningful morbidity and mortality. These are classified as early or late depending on whether they occur before or after 100 days post transplantation. Infectious complications are more common in allogenic HSCT recipients because of graft versus host disease itself and prophylactic and therapeutic immunosuppressive therapy for GVHD [2]. Pulmonary complications of stem cell transfusion (the newest form of BMT) are similar to those related to autologous BMT.
\end{abstract}

Aims and Objectives: To study occurrence of various pulmonary complications in patients undergoing Autologous Bone Marrow Transplantation in Multiple Myeloma patients. To study the interval of appearance of above complications from date of transplantation. To study any change in pulmonary function following transplantation.

Materials and Methods: This Longitudinal Study was conducted in the Department of Clinical Haematology in collaboration with Department of Pulmonary Medicine, SCB Medical College, Cuttack from March-2016 to December-2017.26 patients of Multiple Myeloma who had undergone autologous hematopoietic stem cell transplantation have been included in this study.

Observation: Among 26 patients, Male to female ratio was 2.25:1 and the most common age group overall was 50-59 years (53.85\%). The most common co-morbidity was diabetes mellitus (50\%) followed by hypertension (46.15\%) and COPD (23.08\%). All 3 stages of multiple myeloma had undergone transplantation and the most common being stage - III (16 out of 26 patients 61.54\%). Pulmonary complications appeared in 11 cases out of 26 cases (42.31\%), out of which, 4 were of infective ethology (15.38\%) and 7 were of non-infective ethology (26.93\%).

Conclusion: Understanding the mechanism of lung injury post BMT and developing effective preventive and therapeutic strategy may prevent severe form of pulmonary complications.

Keywords: Bone Marrow Transplantation; Multiple Myeloma

Abbreviations: HSCT: Hematopoietic Stem Cell Transplantation; BMT: Bone Marrow Transplantation

\section{Introduction}

Hematopoietic Stem Cell Transplantation (HSCT) has become the standard technique of Bone Marrow Transplantation (BMT). The first successful allogenic BMT was performed in late 1960s. Since then BMT has been used with increasing frequency for the treatment of malignant and non-malignant haematological diseases, solid tumours, metabolic diseases and genetic diseases. The donor source may be the patient himself (autologous), a sibling or an unrelated person (allogenic), identical twin (syngeneic) or a genetically unrelated umbilical cord blood sample [3]. BMT is a standard therapy for aplastic anaemia, acute leukaemia's, chronic myelogenous leukaemia, non-Hodgkin's lymphoma and Hodgkin's disease with long-term disease-free survival exceeding $60 \%$ [1]. Also encouraging results are noted in the role of BMT in the management of hemoglobinopathies, immunodeficiency 
disorders, myelodysplastic syndromes, multiple myeloma and testicular and breast cancers [1]. Pulmonary complications which occurs in $40 \%-60 \%$ of patients who received BMTs, account for meaningful morbidity and mortality. The spectrum of pulmonary complications includes infectious and non-infectious conditions. These are classified as early or late depending on whether they occur before or after 100 days post transplantation. Mortality rates of HSCT recipients with pulmonary infiltrates requiring mechanical ventilation approach 90\% [4]. Conditioning regimen, reconstitution of immune system and prophylactic strategy for infections influence the incidence of pulmonary complications following HSCT. Infectious complications are more common in allogenic HSCT recipients because of graft versus host disease itself and prophylactic and therapeutic immunosuppressive therapy for GVHD [4]. As the incidence of infectious pulmonary complications has diminished as a result of effective prophylactic therapy, non-infectious pulmonary complications have emerged as a major cause of post-HSCT morbidity and mortality [5]. Pulmonary complications of stem cell transfusion (the newest form of BMT) are like those related to autologous BMT.

\section{Aims and objectives}

a) To study occurrence of various pulmonary complications in patients undergoing Autologous Bone Marrow Transplantation in Multiple Myeloma patients.

b) To study the interval of appearance of above complications from date of transplantation.

c) To study any change in pulmonary function following transplantation.

\section{Materials and Methods}

This study is a Longitudinal Study with pre-transplant patient evaluation and post-transplant patient follow-ups done thrice, at the end of 1 month, 3months and 6 months, was conducted in the Department of Clinical Haematology in collaboration with Department of Pulmonary Medicine, SCB Medical College, Cuttack, from March - 2016 to December - 2017. An ethical clearance was taken from Institutional ethical committee, SCB Medical College \& Hospital, Cuttack.

\section{Inclusion Criteria}

A total of 26 patients of Multiple Myeloma who had undergone autologous hematopoietic stem cell transplantation have been included in this study. Only multiple myeloma cases have been included in the present study because several studies done in the past had shown that in case of multiple myeloma, autologous bone marrow transplantation has better survival and less morbidity and complication post transplantation in comparison to allogenic transplantations. Multiple Myeloma represents a malignant proliferation of plasma cells derived from a single clone. Diagnosis was made based on serum electrophoresis in which "M-band" was found in case of myeloma patients. After diagnosis patient was given a grade according to ISS (Table 1) for multiple myeloma.
Table1: International staging system.

\begin{tabular}{|c|c|}
\hline Stage & Criterion \\
\hline I & $\beta 2$ micro globulin $<3.5 \mathrm{mg} / \mathrm{l}$ and albumin $>3.5 \mathrm{~g} / \mathrm{l}$ \\
\hline II & not staged I or III \\
\hline III & $\beta 2$ micro globulin $>5.5 \mathrm{mg} / \mathrm{l}$ \\
\hline
\end{tabular}

Sub-classification:

A: Serum creatinine $<2 \mathrm{mg} / \mathrm{dl}$

B: Serum creatinine $>2 \mathrm{mg} / \mathrm{dl}$

As per the institutional protocol, patient eligible for stem cell transplantation gets treated with 4 cycles of Cyborg regimen (cyclophosphamide + bortezomib + dexamethasone). After 4 cycles, with 1 week interval between each cycle, patient is expected to be free of tumour cells and he/she is considered for stem cell transplantation. Once a patient is considered for stem cell transplantation he has to undergo following tests Complete Blood Count, Serum Electrolytes, Liver Function Test, Renal Function Test, Pulmonary Function Tests (spirometry and DLCO), Cardiological tests (ECG and 2D-Echocardiography), Serum Inflammatory Marker Tests (Serum lactate dehydrogenase (LDH), Serum C-reactive protein ), Random Blood Sugar, Chest $\mathrm{X}$-Ray (Digital), Sputum, if present, Gram staining and culture sensitivity. After all these tests were done and patient was found to be an eligible candidate for stem cell transplantation patient was explained about the whole procedure, its complication and expected results. After written and informed consent, the patient was taken inside the "Transplantation Suite" and the process was started with all aseptic measures. 1-2 days following infusion of cryopreserved stem cells, patient was administered with growth factor Filgrastim at a dose of 1 vial of $300 \mu \mathrm{g}$ per day subcutaneously for 7 consecutive days.

Table 2: Staging of multiple myeloma.

\begin{tabular}{|c|c|c|c|c|c|}
\hline Stage & & Number & Percentage (\%) & Total & \% \\
\hline I & A & 1 & 3.85 & 1 & 3.85 \\
\hline & B & 0 & 0 & & \\
\hline II & A & 7 & 26.92 & 9 & 34.61 \\
\hline & B & 2 & 7.69 & & \\
\hline III & A & 12 & 46.16 & 16 & 61.54 \\
\hline & B & 4 & 15.38 & & \\
\hline TOTAL & & 26 & 100 & 26 & 100 \\
\hline
\end{tabular}

Patient was also administered with medication for graft versus host disease prophylaxis like Methotrexate tablets only. Weekly serum tests to check for CMV antigenemia, HSV and Parvo virus antigenemia were carried out along with alternate day complete blood count, serum lactate dehydrogenase, serum electrolytes and serum urea, creatinine to check for blood cell recovery and other organ status. In all 26 cases of this study engraftment had taken place within 12-15 days post transplantation. For engraftment to be completed a target of absolute neutrophil count of $0.5 \times 10^{9}$ / 1 and that of platelets $20 \times 10^{9} / 1$ maintained for 3 consecutive days was taken. The decision regarding the discharge of patients 
were taken according to the clinical stability and blood profile of the patient. Excluding 3 patients who died inside the BMT suite, other 23 patients were discharged around 16-17 days post transplantation (Table 2). Patients were discharged with medications like methotrexate and multivitamin tablets.

\section{Exclusion Criteria}

There are no special exclusion criteria for this study. Only prerequisite is that the patient's cardiological and pulmonary fitness status must be up to the standard so that he/she can be expected to undergo the procedure well.

\section{Follow-Up of The Patients Post Transplantation}

Patients were followed up in the department of clinical haematology as per the following protocol. For the $1^{\text {st }}$ month post transplantation weekly follow-up was done. In each followup complete blood count along with peripheral smear, serum electrolytes, renal function tests, serum test for CMV antigenemia, serum lactate dehydrogenase were done. If everything was normal, then patient was discharged with same medication. After $1^{\text {st }}$ month patient was asked for once in a month follow-up. In each of those follow-ups same tests were done. This procedure was continued up to 1 year. For the purpose of this study 3 follow-ups were considered. They were follow-ups at the end of $1^{\text {st }}$ month, at the end of $3^{\text {rd }}$ month and at the end of $6^{\text {th }}$ month since they represented 3 phases of time durations for all the pulmonary complications, Phase-I (0-30 days), Phase-II (31-100 days) and Phase-III ( $>100$ days) respectively. If any patient suddenly developed complication before end of 1 month then he/she was taken in first follow-up irrespective of time.

During the above three follow-ups, besides the above tests, few other tests were done.

1. Complete and proper clinical examination of upper and lower respiratory tract and examination of chest proper under four broad headings i.e. inspection, palpation, percussion and auscultation.

2. Chest X-ray Posterior-anterior view (digital)

3. Electrocardiogram

4. Pulmonary function tests (both spirometry and Delco)

5. C-Reactive Protein (CRP) quantitative.

If the patient complained about any specific symptoms, then other tests were done.

a) Sputum for Gram's staining and culture sensitivity if patient complained of cough with expectoration.

b) Serum Pro-calcitonin (PCT) was done if patient had complained like fever, cough with expectoration, breathlessness and with x-ray suggestive of pneumonia to figure out whether the infection was due to bacterial, viral or fungal origin. c) 2D-Echocardiography if patient complained of breathlessness.

d) High-resolution CT scan of thorax if patient had developed breathlessness along with interstitial or any ambiguous opacity in x-ray done earlier.

e) Fibre-optic Bronchoscopy if patient complained of cough and breathlessness but had no findings that fully explained the symptoms on x-ray and HRCT scan thorax.

The purpose of doing bronchoscopy was to collect samples like bronchoalveolar lavage and bronchial wash to detect pathologies like diffuse alveolar haemorrhage and to exclude infection so that diagnosis of idiopathic pneumonia syndrome, bronchiolitis obliterans syndrome could be established. Bronchoscopy was done in department of pulmonary medicine using PENTAX video assisted bronchoscope [Model no: EB 1970 TK (3.2)] after the patient was nil-per-oral for at-least 8 hours before procedure (Table 3). We had used local anaesthesia. 2\% lignocaine jelly was applied deep inside the both nostrils and 10\% lignocaine solution was also sprayed into the mouth. Bronchoscope was manoeuvred up to segmental bronchi. Bronchoalveolar lavage were obtained with flexible fibre optic bronchoscope. $100 \mathrm{ml}$ of sterile saline at room temperature was infused in five $20 \mathrm{ml}$ aliquots through the bronchoscope wedged into a subsegmental bronchus. After each aliquot was infused the fluid was recovered by using suction apparatus and collected in a sterile specimen trap. The specimens were then pooled in a sterile plastic cup and sent for examinations. BAL fluid was checked for colour and was sent for cytological and bacteriological examinations. The development of pneumothorax, haemorrhage, infection and cardiac arrhythmias were looked for 24-48 hours. Surgical lung biopsy was planned for those patients suspected of bronchiolitis obliterans syndrome to confirm the diagnosis if risk-benefit ratio allowed it. In our study no patient was subjected for surgical lung biopsy.

Table 3: Respiratory symptoms in post BMT patients.

\begin{tabular}{|c|c|c|c|}
\hline Symptoms & Number (\%) & Number (\%) & Number (\%) \\
\hline & $\begin{array}{c}\text { At } 1^{\text {st }} \text { follow- } \\
\text { up } \\
(\mathrm{n}=26)\end{array}$ & $\begin{array}{c}\text { At } 2^{\text {nd }} \text { follow- } \\
\text { up } \\
(\mathrm{n}=23)\end{array}$ & $\begin{array}{c}\text { At } 3^{\text {rd }} \text { follow- } \\
\text { up }\end{array}$ \\
\hline (n= 23)
\end{tabular}

\section{Observation}

A total of 26 cases were studied. Among them 18 were male $(69.24 \%)$ and 8 were female $(30.76 \%)$ cases. Most common age group overall was $50-59$ years (53.85\%). Male to female ratio was 2.25:1. Overall most common BMI group was that of $>22.5 \mathrm{~kg} / \mathrm{m}^{2}$ 
(53.85 \%) out of which 8 were male $(30.8 \%)$ and 6 (23.1\%) were females. But in males most common BMI group was that of 18.5 $-22.5 \mathrm{~kg} / \mathrm{m}^{2}, 9$ cases out of $18(50 \%)$. In females 6 out of 8 cases (75\%) had $>22.5 \mathrm{~kg} / \mathrm{m}^{2}$ BMI. In this study the most common comorbidity was diabetes mellitus found in 13 cases (50\%). $2^{\text {nd }}$ most prevalent comorbidity was hypertension in 12 cases $(46.15 \%)$. 6 patients (23.08\%) had COPD. 4 patients (15.38\%) had dual comorbidities of diabetes and hypertension whereas 2 patients (7.69\%) had combination of all three comorbidities. 6 patients had no comorbidities (23.08 \%) (Table 3). In this study smokers were 9 out of 26 cases (34.62\%) and all were male. No female was a smoker. In this study all 3 stages of multiple myeloma had undergone transplantation. Most common among them were stage-III (16 out of 26 patients 61.54\%), specifically stage-III A (12 out of 26 patients $46.16 \%$ ). $2^{\text {nd }}$ most common stage was stageII A (7 out of 26 cases, $26.92 \%$ ). In our study 16 cases (61.54\%) were found to have normal x-rays and rest 10 patients (38.46\%) had abnormal chest x-rays. Most common abnormal finding was that of emphysematous changes in 6 out of 26 cases $(23.07 \%)$. One patient had both fibrosis and calcification in right upper zone suggestive of healed tuberculosis. In this study out of 26 patients, $22(84.62 \%)$ had FEV1/FVC ratio $>70 \%$ of predicted suggesting either normal or restrictive pattern. 4 patients had FEV1/FVC ratio $<70 \%(15.38 \%)$ of predicted value indicating obstruction. 3 patients (11.54\%) out of 26 had diminished Delco (Delco $<80 \%$ of predicted) indicating restriction (Table 4). All patients undergoing hematopoietic stem cell transplantation were followed at the end of 1 month, 3 months and 6 months. The most common symptoms during $1^{\text {st }}$ follow-up at the end of 1 month or at the first instance of start of a suspected respiratory complication (for those patients who developed complications during their initial hospitalisation itself) were cough with or without expectoration and breathlessness found in 6 cases out of 26 patients (23.07\%). During $2^{\text {nd }}$ follow-up at the end of $3^{\text {rd }}$ month only 1 case developed cough with dyspnoea out of 23 patients (4.35\%) (since 3 patients had died). During $3^{\text {rd }}$ follow up at the end of $6^{\text {th }}$ month 3 patients had dry cough with dyspnoea out of 23 cases (13.04\%). In this study during $1^{\text {st }}$ follow-up most common x-ray finding was that of patchy consolidations, 4 out of 26 cases (15.38\%) followed by lobar consolidations in 2 out of 26 cases (7.69\%). 7 patients (26.92\%) had pre-transplant findings (6 cases with emphysematous changes and 1 case with fibrosis and calcification). Rest 12 cases (46.15\%) were normal. During $2^{\text {nd }}$ follow-up no extra abnormal findings were elicited. Out of 23 patients ( 3 patients had died) 5 cases $(21.74 \%)$ had pre-transplant changes and rest 18 cases (78.26\%) were normal. At the time of $3^{\text {rd }}$ follow-up most common abnormal finding was also that of hyperinflation,3 out of 23 cases (13.04\%). 5 patients $(21.74 \%)$ had pre-transplant changes. Rest 15 cases $(65.22 \%)$ were normal. In this study only those cases who had suspected pulmonary complications had undergone HRCT scan. So total 11 patients had undergone HRCT at different time of follow-ups. Most common HRCT finding overall was infiltrations in 4 cases (36.36\%) followed by ground glass opacity and mosaic pattern with air-trapping, 3 cases each (27.27\%). 2 cases each had consolidation and bronchiectasis and 1 case had interlobular septal thickening (Table 5).

Table 4: Chest X-RAY findings during follow-UPS.

\begin{tabular}{|c|c|c|c|c|}
\hline Findings & & $\begin{array}{c}\text { Number } \\
(\%)\end{array}$ & $\begin{array}{c}\text { Number } \\
(\%)\end{array}$ & $\begin{array}{c}\text { Number } \\
(\%)\end{array}$ \\
\hline & & $\begin{array}{c}\text { At } 1^{\text {st }} \\
\text { follow-up }\end{array}$ & $\begin{array}{c}\text { At } 2^{\text {nd }} \\
\text { follow-up }\end{array}$ & $\begin{array}{c}\text { At } 3^{\text {rd }} \\
\text { follow-up }\end{array}$ \\
\hline & & $(n=26)$ & $(n=23)$ & $(n=23)$ \\
\hline Hyperinflation & & $0(0)$ & $0(0)$ & $3(13.04)$ \\
\hline $\begin{array}{c}\text { Lobar } \\
\text { consolidation }\end{array}$ & & $2(7.69)$ & 0 & 0 \\
\hline $\begin{array}{c}\text { Patchy } \\
\text { consolidation }\end{array}$ & & $4(15.38)$ & 0 & 0 \\
\hline Effusion & & $1(3.85)$ & 0 & 0 \\
\hline Reticular & & 0 & 0 & 0 \\
\hline Nodular & & 0 & 0 & 0 \\
\hline \multirow[t]{2}{*}{$\begin{array}{l}\text { Pretransplant } \\
\text { abnormalities }\end{array}$} & Emphysema & $6(23.07)$ & $4(15.38)$ & $4(15.38)$ \\
\hline & $\begin{array}{c}\text { Fibrosis \& } \\
\text { calcification }\end{array}$ & $1(3.85)$ & $1(3.85)$ & $1(3.85)$ \\
\hline Normal & & 12 (46.15) & $18(78.26)$ & $15(65.22)$ \\
\hline
\end{tabular}

Table 5: Follow-up HRCT findings.

\begin{tabular}{|c|c|}
\hline HRCT findings & Numbers (n= 11) \\
\hline Ground glass opacity & $3(27.27)$ \\
\hline Mosaic pattern (air-trapping) & $3(27.27)$ \\
\hline Bronchiectasis & $2(18.18)$ \\
\hline Consolidation & $2(18.18)$ \\
\hline Infiltration & $4(36.36)$ \\
\hline Septal thickening & $1(9.09)$ \\
\hline
\end{tabular}

In this study sputum analysis were done in 16 patients out of 26 cases. On gram's staining of sputum mixed organism were isolated in 7 cases $(26.92 \%)$. Gram positive cocci were isolated in 5 cases $(19.23 \%)$ and gram-negative bacilli were found in 3 cases $(11.58 \%)$. In this study two parameters have decreased consistently over time and during subsequent follow-ups. They are FEV 1/ FVC ratio and Delco. Other four parameters had no relationship between pre-transplant values and follow-up at $1^{\text {st }}$ month and $3^{\text {rd }}$ month. But they all had decreased at $6^{\text {th }}$ month follow-up in this study pulmonary complication appeared in 11 cases out of 26 cases (42.31\%). Rest 15 cases (57.69\%) had no pulmonary complications.

In this study overall pulmonary complications were found to be 11 out of 26 cases (42.31\%). Out of 11 complications, 4 were of infective ethology (15.38\%) and 7 were of non-infective ethology (26.93\%). In this study there were 7 non-infectious pulmonary complications 1 . Out of 7 cases most common noninfectious complication was Bronchiolitis Obliterans Syndrome found in 3 cases (11.54\%) followed by that of isolated decrease in Delco elicited in 2 cases (7.69\%). Diffuse alveolar haemorrhage 
and idiopathic pneumonia syndromes were found in 1 case each (3.85\%) (Table 6). No cases with COP and DPTS were found. In this study, we had 4 cases who showed infective pulmonary complications out of 26 patients (15.38\%). Out of 4 cases 2 cases had bacterial etiologist (50\%) and other 2 had viral etiologist (50\%). In the 2 cases with bacterial origin, both patients were male and organisms were streptococcus pneumonia and klebsiella pneumonia. In the 2 cases with viral origin, both patients were female, and organisms were cytomegalovirus and parvo virus. In this study it was clear that the most common time frame post transplantation for complications was phase-I when 6 out of $11(54.55 \%)$ complications arise followed by phase-III when 4 complications (36.36\%) were found. All 4 infectious complications happened during phase-I. Non-infectious complications were most common during phase-III.

Table 6: Sputum analysis during follow-UPS.

\begin{tabular}{|c|c|}
\hline Organisms & numbers (\%) \\
\hline Gram positive cocci & $5(19.23)$ \\
\hline Gram negative bacilli & $3(11.58)$ \\
\hline Gram positive bacilli & $1(3.85)$ \\
\hline Mixed & $7(26.92)$ \\
\hline Not done & $10(38.46)$ \\
\hline Total & $26(100)$ \\
\hline
\end{tabular}

It was found that different non-infectious complications had occurred in different phases. Most common time period for BOS was phase-III when 2 out of 3 cases developed. Other BOS case was found in phase-II. Both DAH and IPS had occurred in phase-I. Most common time frame for isolated decrease in Delco was phase-III when all 2 cases developed. In this study out of 26 cases 4 patients have died (15.38\%). Out of 4 cases, 3 cases had noninfective ethology and 1 case had infective ethology. Out of noninfectious ethology IPS, BOS and DAH all were responsible for 1 case each and patients died on $10^{\text {th }}, 201^{\text {st }}$ and $4^{\text {th }}$ post-transplant day respectively (Table 7). 1 death occurred due to infectious ethology (CMV pneumonia) who died on $8^{\text {th }}$ post-transplant day. In this study, overall most complications occurred in patients with stage-III A ( 6 cases out of $11,54.55 \%) .2^{\text {nd }}$ most common stage where complications were found was stage - IIA (4 out of 11 cases, $36.36 \%$ ). Non-infectious complications were most common in stage-III A ( 5 out of 11 cases, $45.46 \%$ ). Infectious complications were most common in stage-II A (2 cases out of 11, 18.18\%). Most common co-morbidity with pulmonary complications was Hypertension, 6 out of 11 cases (54.55\%) followed by Diabetes Mellitus, 5 out of 11 cases (45.45\%) (Table 8). For infectious complications most common comorbidity was hypertension, 3 cases (27.27\%). For non-infectious complications most common co-morbidities were diabetes mellitus and COPD each with 4 cases $(36.36 \%)$.

Table 7: Post transplantation pulmonary function changes (Mean Values)

\begin{tabular}{|c|c|c|c|c|c|c|c|}
\hline Parameters & $\begin{array}{c}\text { Pre-transplant } \\
\text { evaluation }\end{array}$ & First follow-up & P-value & 2nd follow-up & P-value & 3rd follow-up & P-value \\
\hline & & (AT 1 MONTH) & & (AT 3 MONTHS) & & (AT 6 MONTHS) \\
\hline FEV 1 & $87 \pm 9.13$ & $88.75 \pm 6.51$ & & $87.13 \pm 8.02$ & & $83.17 \pm 13.65$ & $75.91 \pm 7.55$ \\
\hline FVC & $76.73 \pm 10.89$ & $77.45 \pm 10.59$ & & $74 \pm 3.51$ & & $89.17 \pm 19.14$ & \\
\hline FEV 1/ FVC & $99.15 \pm 14.12$ & $94.55 \pm 3.05$ & & $93.09 \pm 10.02$ & & $5.44 \pm 0.64$ & \\
\hline TLC & $5.67 \pm 0.49$ & $5.51 \pm 0.58$ & & $5.68 \pm 0.15$ & & $1.43 \pm 0.39$ & \\
\hline RV & $1.51 \pm 0.32$ & $1.45 \pm 0.25$ & & $1.53 \pm 0.64$ & & $87.3 \pm 12.0$ & \\
\hline DLco & $92.88 \pm 7.42$ & $90.3 \pm 3.51$ & & $90.1 \pm 12.16$ & & \\
\hline
\end{tabular}

(All values given here are mean values of all patients)

Table 8: Pulmonary Complications.

\begin{tabular}{|c|c|c|}
\hline Patients & Numbers & Percentage (\%) \\
\hline With complications & 11 & 42.31 \\
\hline Without complications & 15 & 57.69 \\
\hline Total & 26 & 100 \\
\hline
\end{tabular}

\section{Discussion}

Both infectious and non-infectious pulmonary complications have been part and parcel of hematopoietic stem cell transplantation since the beginning of this procedure. In this longitudinal study we had taken 26 cases who had undergone autologous haematopoietic stem cell transplantation, which is comparable to studies by F Patriarca [6] \& Frederick Schlemmer [7] who had sample sizes of 40 and 39 cases respectively (Table
9). The smaller sample size because we had considered only multiple myeloma patients. Most of the patients belonged to the age group 50-59 years (53.85\%) followed by age group 40-49 years $(30.76 \%)$. Majority of our patients were male (69.24\%) compared to females (30.76\%) with male to female ratio of 2.25:1, which is in accordance with study by Frederic Schlemmer $(\mathrm{M}: \mathrm{F}=2.33: 1)$ [7], F.Patriarca $(\mathrm{M}: \mathrm{F}=2.25: 1)$ [6], and E Sakaida ( $\mathrm{M}: \mathrm{F}=2.2: 1)[8]$. The most common BMI group that had undergone transplantation in this study is $>22.5 \mathrm{~g} / \mathrm{m}^{2}(53.85 \%)$ which was also the most common group for females. For males the most common BMI group was $18.5-22.5 \mathrm{~kg} / \mathrm{m}^{2}$ (34.65\%). In this study smokers constituted $34.62 \%$ of patients and all cases were male, which is more or less similar to the study by F Schlemmer [7] \& F Patriarca [6]. In this study pre-transplant spirometry values (mean) of FEV1, FVC and FEV1/FVC were $87 \pm 9.13,76.73 \pm 10.89$, 
99.15 \pm 14.12 respectively. F Patriarca [6] had pre-transplant FEV1/FVC mean value as $83.7 \pm 8.2$. Kenji Matsumoto [9] had pretransplant mean value of FEV1 as $90 \pm 17$. This study matches with the above studies. Post transplantation spirometry mean values in this study for FEV1 and FEV1/FVC at the end of 3 months were $87.13 \pm 8.02$ and $93.09 \pm 10.02$ respectively.

Table 9: Types of Pulmonary Complications.

\begin{tabular}{|c|c|c|}
\hline Pulmonary complications & Number & Percentage \\
\hline & & $(\mathrm{n}=26)$ \\
\hline Infectious & 4 & 15.38 \\
\hline Non-infectious & 7 & 26.93 \\
\hline Total & 11 & 42.31 \\
\hline
\end{tabular}

In the study of F Patriarca [6] mean values of FEV1/FVC at 3 months post transplantation was $85 \pm 6.5$. Our study is more or less similar to their study. But, in the study of Kenji Matsumoto [9] mean values of FEV1 and FEV1/FVC at the end of 3 months were $93 \pm 16$ and $102 \pm 12$ respectively, which does not match with the above study. Lower values in our study may be due to higher average age of patients.In this study pulmonary complications were found in $42.31 \%$ cases (Table 10), of which non-infectious complications constituted $26.93 \%$ and infectious complications constituted $15.38 \%$. In similar studies like that of Kasem Sirithanakul [10], Kenji Matsumoto [9], F Patriarca [6], E Sakaida [8] all had pulmonary complications in the range of $40-60 \%$. Pulmonary complications among males were $44.44 \%$ and among females were $37.5 \%$. Males predominantly had non-infectious pulmonary complications (75\%), whereas Females predominantly had infectious pulmonary complications (66.67\%).

Table 10: Incidence of non-infectious pulmonary complications.

\begin{tabular}{|c|c|c|}
\hline NIPCs & Number & \% Out of all Cases \\
\hline & & $(\mathrm{n}=26)$ \\
\hline BOS & 3 & 11.54 \\
\hline DAH + PE & 1 & 3.85 \\
\hline IPS & 1 & 3.85 \\
\hline$\downarrow$ in DLco & 2 & 7.69 \\
\hline COP & 0 & 0 \\
\hline DPTS & 0 & 0 \\
\hline TOTAL & 7 & 26.93 \\
\hline
\end{tabular}

In the study by Zuhre Kaya [11] incidence of infectious complications (48.2\%) were more in comparison to that of non-infectious complications (28.18\%). Incidence of BOS in our study is $11.54 \%$, among which $66.67 \%$ in phase-III and $33.33 \%$ in phase-II and that is similar to that of all the studies by Kasem Sirithanakul (2-11\%) [10], I Khurshid (2-14\%) [12] and Kenneth T. Yen (6-10\%) [13]. Similarly in this study incidence of IPS out of all cases is $3.85 \%$ and all cases during phase-I (100\%), similar to the study Ayman O Soubani [1], where incidence of IPS was 5.8\% in autologous cases and D.H.Lim [14] where overall incidence of IPS was $1.4 \%$. DH Lim [14] had occurrence of IPS in phase-II and
phase-III, 50\% each. Kasem Sirithanakul [10] had occurrence of IPS around 3 week-3-month period. Ayman O Soubani [1] had occurrence of IPS around 42-49 days. In this study incidence of DAH with Pulmonary Enema is 3.85\%, and this matches with the studies of Ayman O Soubani [1], DH Lim [14] \& Ron Ben Abraham [15] were $5 \%, 2.1 \%$ and $4.3 \%$ respectively. In our study there is no incidence of COP. In studies by Freudenberger [16] and Ayman 0 Soubani [17] incidence of COP was $1 \%$ and $2 \%$ respectively which had occurred exclusively in allogenic transplantation cases (Table 11). Our study that includes only autologous cases matches with the descriptions of above studies.

Table 11: Incidence of infectious pulmonary complications.

\begin{tabular}{|c|c|c|}
\hline Infectious complications & Number & \% out of total cases \\
\hline & & $(\mathrm{n}=26)$ \\
\hline Bacterial pneumonia & 2 & 7.69 \\
\hline Viral pneumonia & 2 & 7.69 \\
\hline Fungal pneumonia & 0 & 0 \\
\hline Pneumocytis pneumonia & 0 & 0 \\
\hline Total & 4 & 15.38 \\
\hline
\end{tabular}

In this study incidence of bacterial pneumonia is $7.69 \%$ among which organisms responsible are Streptocoocus 50\% and Klebsiella 50\%. In the study of Catherine Cordorennier [18] they had H. Influenza $37.5 \%$ and streptococcus, pseudomonas, listeria and legionella each of $12.5 \%$. Do H Lim [14] had found incidence of bacterial pneumonia to be $6.73 \%$ out of all cases. Our study matches with this study. In other studies, like that of Catherine Cordorennier [18] they had incidence of bacterial pneumonia, out of all pulmonary complications, as $19.51 \%$. Our study shows incidence of bacterial pneumonia out of all pulmonary complications to be around $18.18 \%$. So, our study matches with the above study (Table 12). In this study incidence of viral pneumonia is $7.69 \%$ and the organisms causing viral pneumonia were CMV and parvovirus each comprising $3.85 \%$. Do H Lim [14] had incidence of viral pneumonia as $2.44 \%$. Our study does not match with their study higher incidence of viral pneumonia may be because of overall older age of our patients (Table 13). In their study KT Yen [13] had incidence of CMV pneumonia to be around $10 \%$ and Catherine Cordonnier [18] incidence of CMV pneumonia was 13\%. There was no incidence of fungal pneumonia. In their studies, Do H Lim [14], Ayman 0 Soubani [1], Kasem Sirithanakul [10] had incidences of fungal pneumonia as $2.1 \%, 10 \%$ and $4 \%$ respectively. Our study does not match with their study because of low sample size (Table 14), autologous transplantation, maintaining a high degree of aseptic measures and avoidance of other risk factors like construction work near transplantation unit, storage facilities near ward etc. In this study stage-III A multiple myeloma patients had the greatest number of complications (23.07\%) out of all cases followed by stage- IIA (15.38\%). In this study most pulmonary complications were associated with co-morbidity like hypertension and diabetes 6 cases and 5 cases respectively out of all patients (Table 15). 4 
complications were associated with pre-existing COPD out of which 3 had non-infectious pulmonary complications.

Table 12: Duration of appearance of pulmonary complications.

\begin{tabular}{|c|c|c|c|c|c|c|}
\hline & Non-infectious & & Infectious & & Total & \\
\hline \multirow[t]{2}{*}{ Time duration } & Complication & & Complications & & & \\
\hline & No & $\%$ & No & $\%$ & No & $\%$ \\
\hline Phase-I & 2 & 18.19 & 4 & 36.36 & 6 & 54.55 \\
\hline \multicolumn{7}{|l|}{ (0-30 days) } \\
\hline Phase - ii & 1 & 9.09 & 0 & 0 & 1 & 9.09 \\
\hline \multicolumn{7}{|l|}{ (31-100 days) } \\
\hline Phase - iii & 4 & 36.36 & 0 & 0 & 4 & 36.36 \\
\hline \multicolumn{7}{|l|}{ (>100 days) } \\
\hline Total & 7 & 63.64 & 4 & 36.36 & 11 & 100 \\
\hline
\end{tabular}

Table 13: Duration of appearance of non-infectious pulmonary complications.

\begin{tabular}{|c|c|c|c|c|c|c|c|c|}
\hline $\begin{array}{l}\text { Non-infectious pulmonary } \\
\text { complications }\end{array}$ & phase- I (0-30 days) & & phase - ii (31-100 days) & & phase- iii (> 100 days) & & total & \\
\hline & No & $\%$ & No & $\%$ & No & $\%$ & No & $\%$ \\
\hline BOS & 0 & 0 & 1 & 3.85 & 2 & 7.69 & 3 & 11.54 \\
\hline Dah + pe & 1 & 3.85 & 0 & 0 & 0 & 0 & 1 & 3.85 \\
\hline IPS & 1 & 3.85 & 0 & 0 & 0 & 0 & 1 & 3.85 \\
\hline Isolated decrease in DLCO & 0 & 0 & 0 & 0 & 2 & 7.69 & 2 & 7.69 \\
\hline total & 2 & 7.69 & 1 & 3.85 & 4 & 15.38 & 7 & 26.92 \\
\hline
\end{tabular}

Table 14: Pulmonary complications leading to death.

\begin{tabular}{|c|c|c|}
\hline Pulmonary complications causing death & Numbers & Post-transplantation day of death \\
\hline BOS & 1 & $201^{\text {st }}$ day \\
\hline IPS & 1 & $10^{\text {th }}$ day \\
\hline DAH + PE & 1 & $4^{\text {th }}$ day \\
\hline CMV PNEUMONIA & 1 & $8^{\text {th }}$ day \\
\hline TOTAL & 4 & -- \\
\hline
\end{tabular}

Table 15: Relation between staging and pulmonary complications.

\begin{tabular}{|c|c|c|c|c|c|c|}
\hline Stage & Infectious complication & & Non-infectious complications & & Total & \\
\hline & NO & $\%$ & NO & $\%$ & NO & $\%$ \\
\hline IA & 0 & 0 & 0 & 0 & 0 & 0 \\
\hline IB & 0 & 0 & 0 & 0 & 0 & 0 \\
\hline IIA & 2 & 7.69 & 2 & 7.69 & 4 & 15.38 \\
\hline IIB & 0 & 0 & 0 & 0 & 0 & 0 \\
\hline IIIA & 1 & 3.85 & 5 & 19.23 & 6 & 23.08 \\
\hline IIIB & 1 & 3.85 & 0 & 0 & 1 & 3.85 \\
\hline TOTAL & 4 & 15.38 & 7 & 26.92 & 11 & 42.31 \\
\hline
\end{tabular}

\section{Conclusion}

The present study concludes that BMT is an effective and promising therapeutic tool for a number of haematological malignant and non-malignant conditions. Its success however is often limited by the high incidences of complications especially those related to pulmonary systems. Pulmonary complications include both infectious and non-infectious pulmonary complications. Non-infectious complications remain a major cause of morbidity and mortality after hematopoietic stem cell transplantation. Many of these complications are seen in recipients of autologous transplant and they likely result from shared toxicities of administered chemotherapy. In addition, infectious pulmonary complications may happen as a complication of immunosuppressive agents. A better selection of patients, the use of the least toxic conditioning regimen, early recognition and treatment of infectious and non-infectious complications along 
with future efforts focusing on understanding mechanism of lung injury and developing effective preventive and therapeutic strategy may prevent severe form of pulmonary complications.

\section{Limitations}

Short follow-up period which may cause less detection of noninfectious complications like 'BOS' and 'isolated decrease in Delco'. More number of cases might had been detected if bronchoscopy with bronchoalveolar lavage fluid collection was carried out in suspected cases of infectious complications. In our study only autologous HSCT were carried out and only Multiple Myeloma cases were included.

\section{References}

1. Ayman O, Soubani MD, Kenneth B, Miller MD, Paul M, et al (1996) Pulmonary Complications of Bone Marrow Transplantation. CHEST 109: 1066-1077.

2. Lossos IS, Breuer R, Or R, Strauss N, Elishoov H, Naparstek E, etal. (1995) Bacterial pneumonia in recipients of bone marrow transplantation. A five-year prospective study. Transplantation 60(7): 672-678.

3. Wintrobe's Clinical Hematology, 13/E Lippincott, Williams \& Wilkin's Pg-2161

4. Shorr AF, Moores LK, Edenfield WJ, Christie RJ, Fitzpatrick TM (1999) Mechanical ventilation in hematopoietic stem cell transplantation: can we effectively predict outcomes? Chest 116(4): 1012-1018.

5. Afessa B, Litzow MR, Tefferil A (2001) Bronchiolitis Obliterans and other late onset non-infectious pulmonary complications in hematopoietic stem cell transplantation. Bone Marrow Transplantation 28(5): 425-434.

6. Patriarca F, Skert C, Sperotto A, Damiani D, Cerno M, et al. (2004) Incidence, outcome and risk factors of late onset non-infectious pulmonary complications after unrelated donor stem cell transplantation. Bone Marrow Transplantation 33(7): 751-758

7. Schlemmer F, Chevret S, Lorillon G, De Bazelaire C, Peffault de Latour $\mathrm{R}$, et al. (2014) Late Onset non-infectious interstitial ling disease after allogenic hematopoietic stem cell transplantation. Respir Med 108(10): 1525-1533.
8. Sakaida E, Nakaseko C, Harima A, Yokota A, Cho R, et al. (2003) Late onset non-infectious pulmonary complications after allogenic stem cell transplantation are significantly associated with chronic graft versus host disease and with graft-versus-leukemia effect. Blood 102(12): 4236-4242.

9. Kenji M, Satami I, Wataru Y (2013) Clinical Significance of Pulmonary Function Tests in Long-Term Survivors after Myeloablative Allogenic Hematopoietic Stem Cell Transplantation. Open Journal of Blood Diseases 3: 6-12

10. Kasem S, Ana S, Klein JL, Ayman O (2005) Pulmonary Complications Following Hematologic Stem Cell Transplantation. American Journal of Henatology 80: 137-146.

11. Kaya Z, Weiner DJ, Yilmaz D, Rowan J, Goyal RK (2009) Lung Function, Pulmonary Complications and Mortality after Allogenic Blood and Marrow Transplantation in Children. Biol Blood Marrow Transplant 15(7): 817-826.

12. Khurshid I, Anderson LC (2002) Non-infectious pulmonary complications after bone marrow transplantation. Postgrad Med J 78(919): 257-262.

13. Yen KT, Lee AS, Krowka MJ, Burger CD (2004) Pulmonary complications in bone marrow transplantation: a practical approach to diagnosis and treatment. Clin Chest Med 25(1): 189-201.

14. Lim DH, Lee J, Lee HG, Park BB, Peck KR, et al (2006) Pulmonary Complications After Hematopoietic Stem Cell Transplantation. J Korean Med Sci 21(3): 406-411.

15. Ron-Ben Abraham, Gideon Paret, Rinat Cohen, Szold, Oded, et al (2003) Diffuse Alveolar Hemorrhage Following Allogenic Bone Marrow Transplantation in Children. CHEST 124(2): 660-664.

16. Murray, Nadel's Textbook of Respiratory Medicine. $6^{\text {th }}$ Edition, Pp. 1620.

17. Soubani AO, Pandya CM (2010) The spectrum of non-infectious pulmonary complicatins following hematopoietic stem cell transplantation. Hematol Oncol Stem Cell Ther 3(3): 143-157.

18. Cordonnier C, Bernaudin JF, Bierling P, Huet Y, Vernant JP (1986) Pulmonary complications occurring after allogeneic bone marrow transplantation. A study of 130 consecutive transplanted patients. Cancer 58(5): 1047-1054.

Your next submission with Juniper Publishers will reach you the below assets

- Quality Editorial service

- Swift Peer Review

- Reprints availability

- E-prints Service

- Manuscript Podcast for convenient understanding

- Global attainment for your research

- Manuscript accessibility in different formats

( Pdf, E-pub, Full Text, Audio)

- Unceasing customer service

Track the below URL for one-step submission https://juniperpublishers.com/online-submission.php 